\title{
Localized Malignant Gallbladder Neoplasm
}

National Cancer Institute

\section{Source}

National Cancer Institute. Localized Malignant Gallbladder Neoplasm. NCI Thesaurus.

Code C35676.

A malignant neoplasm that arises from the gallbladder and it has not spread to other anatomic sites. 